\title{
ESTIMATIVA DE RECARGA PELO MÉTODO DO BALANÇO HÍDRICO EM UMA BACIA HIDROGRÁFICA COM OCORRÊNCIA DE AQUÍFEROS FRATURADOS
}

\author{
Taison Anderson Bortolin ${ }^{1}$; Pedro Antonio Roehe Reginato ${ }^{2}$; Vania Elisabete Schneider ${ }^{3}$
}

\begin{abstract}
Resumo - A estimativa de recarga é essencial em estudos de disponibilidade, modelagem e proteção de sistemas aquíferos auxiliando a gestão dos recursos hídricos. Existem muitas técnicas utilizadas para avaliar recarga, cada qual com características e aplicações distintas. Neste trabalho foi utilizado o modelo do balanço hídrico associado a um índice de fluxo basal, em uma bacia com ocorrência de aquíferos fraturados inserida na Bacia Hidrográfica Taquari-Antas. Para isso, foram utilizados dados de evapotranspiração calculados pelo método de Thornthwaite e dados de precipitação de um pluviômetro próximo à bacia, abrangendo o período de 1997 a 2006. Para a separação de escoamento utilizou-se o método do BFI padrão apresentado por Whal e Whal (1996). Os resultados obtidos indicam uma taxa de recarga média mensal de $25 \%$ e anual de $18 \%$ em relação à precipitação que ocorre na bacia. Destaca-se a importância do refinamento desta informação, comparando os resultados com outras técnicas que se utilizam de separação de escoamento ou empregam somente o balanço hídrico, a fim de avaliar as diferenças existentes.
\end{abstract}

\begin{abstract}
Recharge's estimated is essential in studies of availability, modeling and protection of water systems assisting in the management of water resources. There are many techniques used to evaluate recharge, each with different characteristics and applications. In this study we used the water balance model associated with a basal flow index, in a basin with the occurrence of fractured aquifers inserted in the Basin Taquari-Antas. For this, evapotranspiration data were calculated by Thornthwaite method and precipitation data from a rain gauge near the basin were used, covering the period from 1997 to 2006 . For the separation of flow used the standard BFI method presented by Whal and Whal (1996). The results indicate a monthly average charging rate of $25 \%$ and an annual $18 \%$ compared to the precipitation occurring in the basin. It highlights the importance of refinement of this information, comparing the results with other techniques that use flow separation or methods that employ the water balance in order to evaluate the differences.
\end{abstract}

Palavras-Chave - Recarga. Aquíferos Fraturados. Balanço Hídrico. Índice de Fluxo Basal.

\footnotetext{
Afiliação: Instituto de Pesquisas Hidráulicas. Av. Bento Gonçalves, 9500, (51) 3308-6686. tabortol@ucs.br

2 Afiliação: Instituto de Pesquisas Hidráulicas. Av. Bento Gonçalves, 9500, (51) 3308-6686. pedro.reginato@ufrgs.br

${ }^{3}$ Afiliação: Instituto de Saneamento Ambiental, Rua Francisco Getúlio Vargas, 1100 (54) 3218-2100. veschnei@ucs.br
} 


\section{Introdução}

A recarga subterrânea é considerada como a quantidade de água que contribui para aumentar a reserva subterrânea permanente ou temporária de um aquífero (Lerner et al., 1990). A sua estimativa é essencial em estudos de disponibilidade, modelagem e proteção de sistemas aquíferos auxiliando a gestão dos recursos hídricos na forma de subsídio à tomada de decisões visando ao uso sustentável destes, minimizando a superexplotação e contaminação (Lerner et al., 1990; Scanlon et al., 2002). Sua estimativa torna-se imprescindível em regiões onde o uso de águas subterrâneas é intenso, como ocorre no estado do Rio Grande do Sul, cuja maioria dos municípios se abastecem das águas subterrâneas armazenadas nos aquíferos fraturados do Sistema Aquífero Serra Geral.

Nesta região, a recarga é facilitada pelo excedente hídrico e pela presença do manto de intemperismo sobrejacente constituído de solos residuais ou transportados, que facilitam o armazenamento da água infiltrada e que percola até o aquífero fraturado (Ribeiro et al., 2014).

Oliveira (2004), comenta que quantificação da recarga de águas subterrâneas é um processo estimativo, uma vez que não é passível de ser medido diretamente, e existem normalmente dificuldades no que concerne à validação dos resultados obtidos pela aplicação de qualquer método. Alguns autores afirmam que a recarga subterrânea é a componente do balanço hídrico mais difícil de ser estimada (Scanlon et al., 2006; Kresic, 2007).

Existem muitas técnicas utilizadas para avaliar recarga, cada qual com características e aplicações distintas. Conforme Scanlon et. al (2002), os fatores como escala de tempo e espaço, objetivos da estimativa, clima, geologia, geomorfologia e hidrologia devem ser avaliados na determinação da melhor técnica a ser empregada. Deve-se considerar também, a facilidade de aplicação do método, custo e disponibilidade de dados (Wahnfried e Hirata, 2005).

Dois métodos muito aplicados em diferentes estudos correspondem ao balanço hídrico (Wanfried e Hirata, 2005; Conicelli, 2014; Albuquerque et al, 2015) e à utilização de um índice de fluxo basal (IFB) que é resultado da separação de escoamento por filtros digitais (Szilagyi, 2003; Mourão, 2007; Freitas, 2010). Conforme Healy (2010), o método do balanço hídrico estabelece um valor residual que contabiliza a diferença entre entradas e as saídas e a variação no armazenamento de um determinado volume do controle tal como uma coluna de solo, bacia hidrográfica ou aquífero. Já o IFB corresponde à fração do escoamento de base, estabelecido como razão entre a vazão de descarga subterrânea e a vazão total.

Considerando estes fatores, este trabalho objetiva apresentar a estimativa de recarga em uma bacia hidrográfica caracterizada pela ocorrência de aquíferos fraturados que fazem parte do Sistema Aquífero Serra Geral (SASG), no estado do Rio Grande do Sul, utilizando o método do balanço hídrico associado a um índice de fluxo basal. 


\section{2. Área de Estudo}

A área de estudo compreende uma sub-bacia do Rio da Prata, que faz parte da bacia hidrográfica Taquari-Antas, localizada na porção nordeste do estado do Rio Grande do Sul, conforme apresenta a Figura 1.

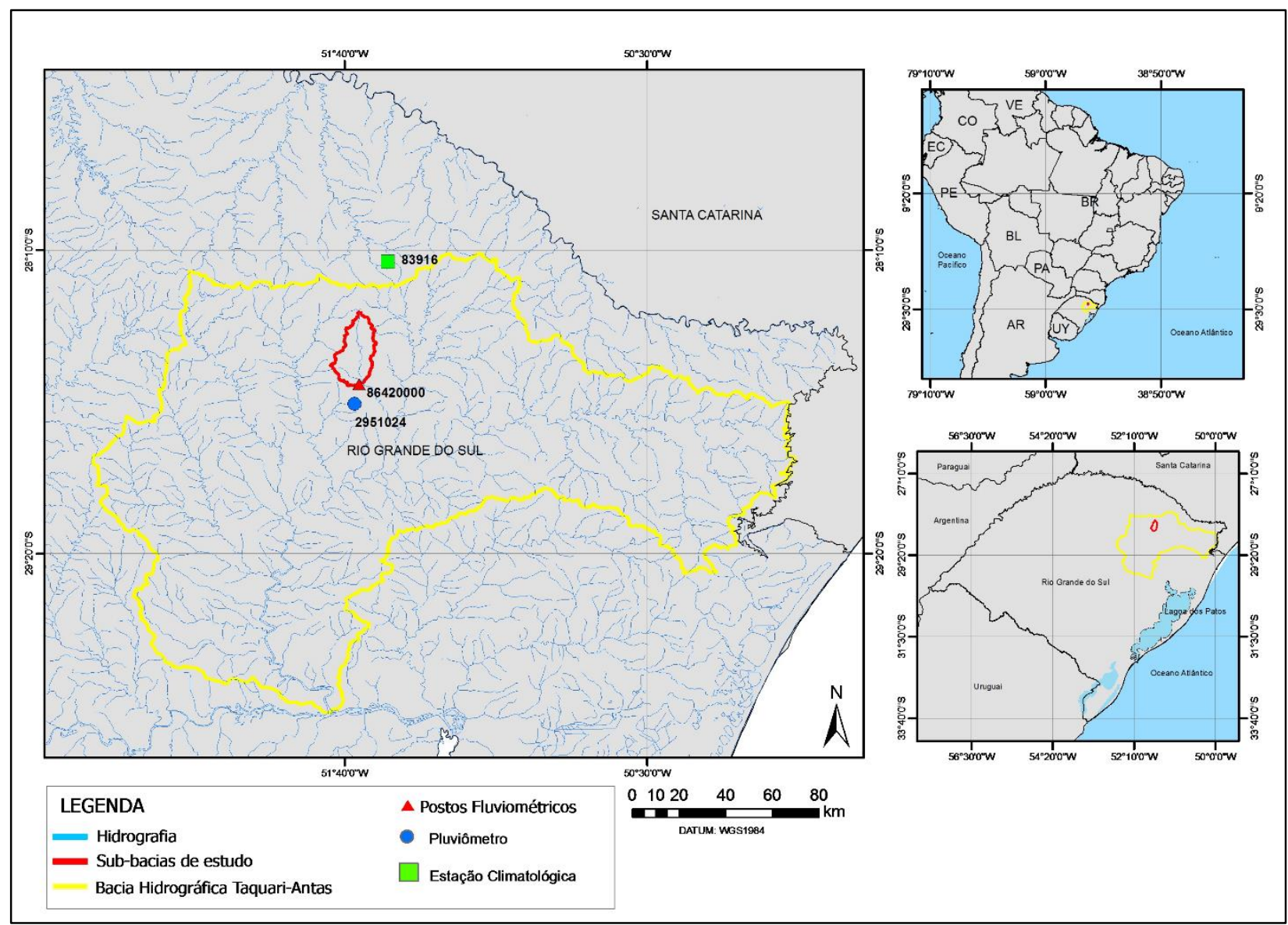

Figura 1- Localização da área de estudo

A bacia possui uma área de $317 \mathrm{~km}^{2}$ com declividade média de 8,24\%. Apresenta uma característica alongada, com maior presença de solos argilosos do tipo latossolos vermelho e em pequena proporção chernossolos argilúvico associado com neossolo litólico.

O clima da área de estudo é caracterizado por Rossato (2011) como subtropical IV, com características de muita umidade, apresentando invernos frios e verões amenos. Possui menor influência dos sistemas polares, com maior atuação dos sistemas tropicais marítimos conjugados com efeito do relevo de altitude do Planalto Basáltico.

Na região de estudo ocorrem chuvas abundantes que oscilam entre 1700 a $2000 \mathrm{~mm}$ anuais bem distribuídas em 130 e 150 dias do ano. Possui, mensalmente, uma média de 12 a 15 dias com chuvas, sendo que no mês de janeiro pode variar entre 15 a 18 dias. O volume mensal de precipitação na maior parte do ano fica em torno de 135 a $175 \mathrm{~mm}$, variando entre 115 e $135 \mathrm{~mm}$ no mês mais seco (março) e 175 a 215 mm no mês mais chuvoso (outubro). Devido à altitude, a região apresenta 
as médias de temperatura mais baixas do estado, variando entre 14 a $17^{\circ} \mathrm{C}$, sendo que no mês mais frio, oscila entre 8 e $14^{\circ} \mathrm{C}$ com temperaturas mínimas médias de 5 a $11^{\circ} \mathrm{C}$. Já no mês mais quente oscila entre $17-23^{\circ} \mathrm{C}$, com temperatura máxima média deste mesmo mês entre 23 a $29^{\circ} \mathrm{C}$.

\subsection{Contexto Geológico}

A área de estudo está inserida na Formação Geológica Serra Geral, caracterizada pela ocorrência de sequências de rochas vulcânicas ácidas e básicas que formam um pacote de rochas com espessura média de 800 metros e máxima de 1500 metros (ROISENBERG; VIERO, 2002). Os derrames de rochas vulcânicas ácidas e básicas possuem estruturas geológicas associadas que seguem um padrão marcado por: uma zona basal em geral maciça, zona central, com disjunções horizontais e verticais e uma zona superior, com presença de vesículas e amigdalas (WILDNER et al., 2006). Conforme o mapa da Figura 2, observa-se que a bacia ainda se insere em duas fácies distintas: a unidade Caxias (rochas vulcânicas ácidas) e a Paranapanema (rochas vulcânicas básicas).

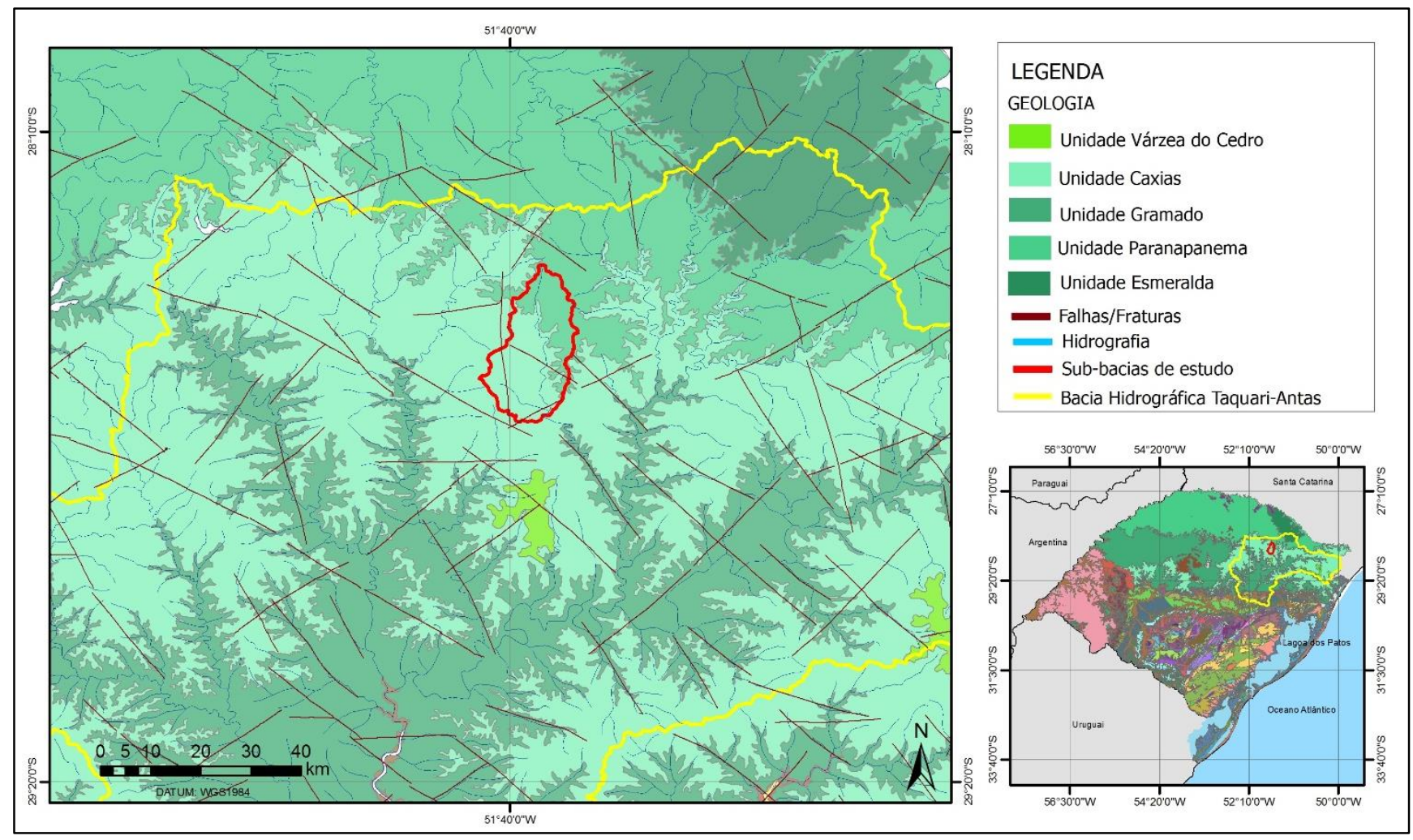

Figura 2 - Contexto geológico da área de estudo

Fonte: elaborado a partir de CPRM (2010)

\subsection{Contexto Hidrogeológico}

A área de estudo está localizada regionalmente na província hidrogeológica do Paraná. De acordo com a Figura 3, a sub-bacia se encontra na área de ocorrência dos Aquíferos Fissurais Serra Geral, mais precisamente no Sistema Serra Geral II, que consiste em aquíferos com média a baixa possibilidade para águas subterrâneas em rochas com porosidade por fraturas (Viero e Silva, 2010). 
Nesta região, segundo Reginato e Strieder (2005), há ocorrência de dois aquíferos principais: granular livre (freático) e o fraturado, os quais podem ou não apresentar conexão. O primeiro está localizado sobre o manto de alteração, e sua exploração ocorre por meio de poços escavados e fontes, utilizado principalmente em zonas rurais. O segundo, com maior vazão, está localizado nas rochas vulcânicas, condicionado principalmente pelas estruturas tectônicas (fraturas) e, secundariamente, pelas estruturas geradas no resfriamento das rochas ou pelo contato entre derrames. É caracterizado como heterogêneo, descontínuo e instável (NANNI, 2008) e possui uma forte anisotropia, vazões variáveis, capacidades específicas e transmissividades baixas (REGINATO e STRIEDER, 2004).

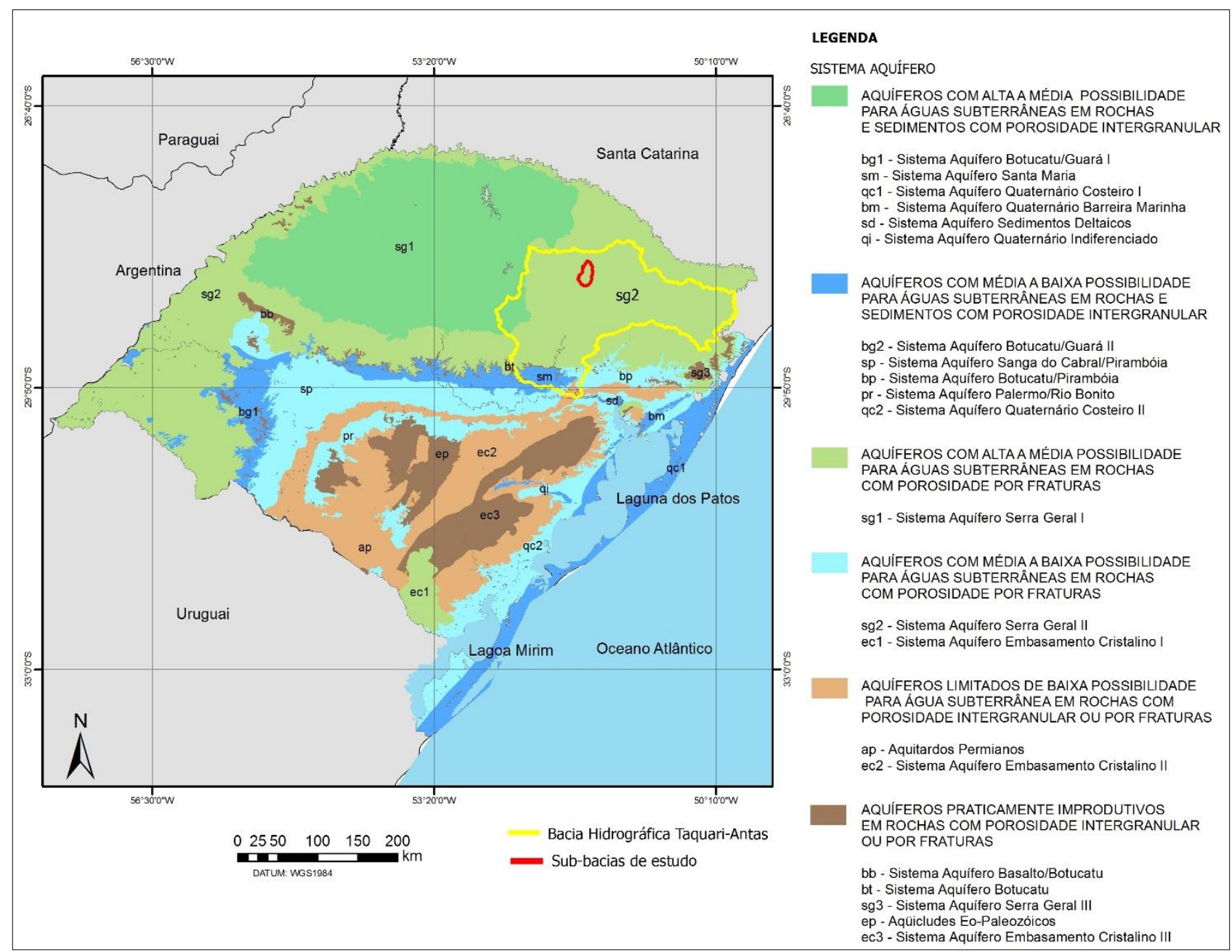

Figura 3 - Contexto Hidrogeológico da área de estudo

Fonte: elaborado a partir de Viero e Silva (2010)

\section{Metodologia (Material e Métodos)}

Para a estimativa de recarga utilizou-se o método proposto por Szilagyi et al. (2003) que aplica o balanço hídrico em uma bacia hidrográfica considerando a seguinte equação:

$$
P=E T+q_{s}+q_{b}+N+\Delta S
$$


Onde P é a precipitação; ET é a evapotranspiração; $q_{s}$ é o escoamento superficial; $q_{b}$ é o fluxo de base, $\mathrm{N}$ corresponde a qualquer entrada ou saída de água, além da precipitação e da evapotranspiração, $\Delta S$ é a variação na reserva de água.

Para longos períodos de tempo, os dados de $\mathrm{N}$ e $\Delta \mathrm{S}$ são desprezíveis, a recarga (R) pode ser considerada igual ao escoamento de base, obtido pela aplicação de um índice de fluxo basal (BFI) ao balanço entre precipitação e evapotranspiração, como mostra a equação 2.

$$
B F I \times(P-E T)=q_{b} \approx R
$$

Equação 2

O BFI, que corresponde a relação de longo prazo entre o escoamento de base a vazão total, foi calculado pelo método BFI-padrão proposto por Wahl e Wahl (1998). Os autores explicam que durante cada intervalo de $\mathrm{N}$-dias, a vazão mínima é identificada e comparada com valores mínimos adjacentes. Se um determinado mínimo é menor do que o fator de teste de ponto de inflexão, $\boldsymbol{f}$, então, esse mínimo é designado como um ponto de inflexão. Esses pontos são então conectados para construir o hidrograma de fluxo de base. Para o método de BFI-padrão, o valor de $\mathrm{N}$ corresponde a 5 dias e $\boldsymbol{f}=90 \%$.

Os dados de precipitação média mensal foram retirados do posto pluviométrico 2951024 , localizado próximo à bacia de estudo, compreendendo o período de 1977 a 2006. Os dados de ET, para o mesmo período, foram obtidos a partir de série de temperaturas médias retiradas da estação meteorológica do Instituto Nacional de Meteorologia (INMET) 83916 - Lagoa Vermelha e calculados conforme a equação de Thornthwaite (1948):

$$
\boldsymbol{E T}=16 \boldsymbol{b}\left(10 \frac{T}{I}\right)^{a}, 0{ }^{\circ} \mathrm{C} \leq \mathrm{T} \leq 26^{\circ} \mathrm{C}
$$

Equação 3

Onde: T é a temperatura média mensal $\left({ }^{\circ} \mathrm{C}\right)$; I é o índice de calor disponível para a região; o expoente 'a' é a função cúbica de I calculado a partir da soma dos índices de calor dos 12 meses; 'b' é um fator de correção referente ao período de insolação durante o dia que varia em função da latitude do local de estudo. O cálculo das variáveis I, a e b é realizado com as seguintes equações:

$$
I=\sum_{j=1}^{12}\left[\frac{T_{j}}{5}\right]^{1,514}
$$

Equação 4

$$
a=6,75 \times 10^{-7} I^{3}-7,71 \times 10^{-5} I^{2}+1,792 \times 10^{-2} I+0,49239
$$


Equação 5

$$
b=\left(\frac{N D}{30}\right) x\left(\frac{N}{12}\right)
$$

Equação 6

Onde ND é o número de dias do mês e $\mathrm{N}$ o fotoperíodo em horas.

\section{Resultados e Discussão}

A tabela 1 apresenta os dados de temperatura, precipitação média obtida a partir das estações e os dados de evapotranspiração calculados, enquanto a Figura 4 apresenta a variação destes parâmetros de forma gráfica ao longo dos meses.

Tabela 1 - Dados utilizados na estimativa de recarga

\begin{tabular}{|c|c|c|c|c|c|c|c|}
\hline Meses & $\begin{array}{c}\text { Num } \\
\text { de } \\
\text { dias }\end{array}$ & $\mathbf{T}\left({ }^{\circ} \mathbf{C}\right)$ & $\mathbf{P}(\mathbf{m m})$ & $\mathbf{N}$ (horas) & $\mathbf{I}$ & $\mathbf{a}$ & $\begin{array}{c}\mathbf{E T P} \\
(\mathbf{m m})\end{array}$ \\
\hline Jan & 30 & 21,2 & 145,0 & 13,83 & 8,93 & 1,73 & 106,22 \\
\hline Fev & 28 & 21,0 & 138,3 & 13,37 & 8,77 & 1,73 & 94,04 \\
\hline Mar & 31 & 20,0 & 110,6 & 12,65 & 8,14 & 1,73 & 90,33 \\
\hline Abr & 30 & 17,2 & 137,6 & 11,73 & 6,50 & 1,73 & 62,68 \\
\hline Mai & 31 & 14,1 & 132,1 & 10,89 & 4,81 & 1,73 & 42,67 \\
\hline Jun & 30 & 13,4 & 139,8 & 10,27 & 4,43 & 1,73 & 35,44 \\
\hline Jul & 31 & 12,4 & 179,6 & 10,16 & 3,93 & 1,73 & 31,59 \\
\hline Ago & 31 & 13,4 & 136,0 & 10,59 & 4,42 & 1,73 & 37,70 \\
\hline Set & 30 & 14,5 & 173,4 & 11,39 & 5,01 & 1,73 & 45,18 \\
\hline Out & 31 & 17,5 & 184,6 & 12,28 & 6,69 & 1,73 & 70,16 \\
\hline Nov & 30 & 18,6 & 140,8 & 13,15 & 7,33 & 1,73 & 80,64 \\
\hline Dez & 31 & 20,1 & 130,0 & 13,73 & 8,20 & 1,73 & 98,99 \\
\hline Total & & & 1748,1 & & & & 795,6 \\
\hline
\end{tabular}

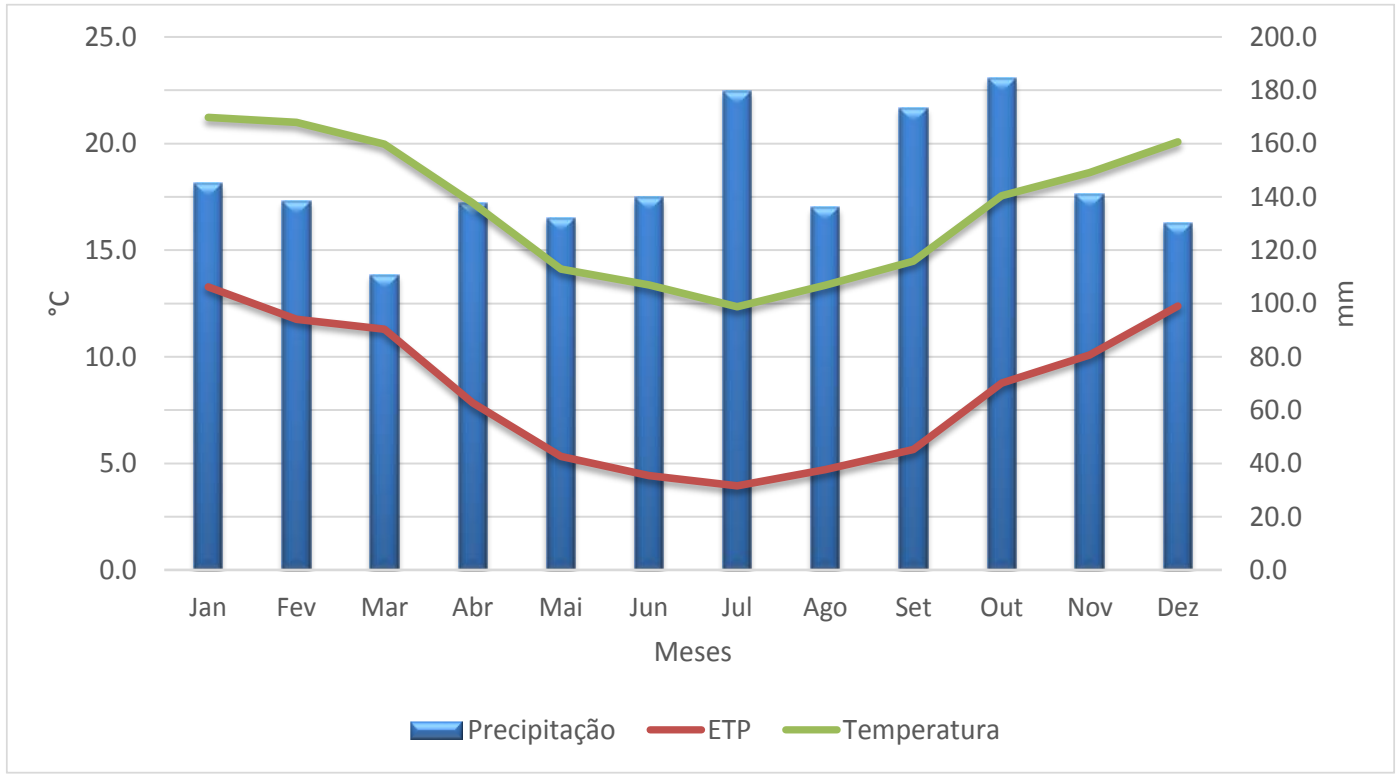

Figura 4 - Variação mensal de precipitação, ETP e temperatura 
As maiores precipitações no período analisado correspondem aos meses de julho e outubro, evidenciando um período úmido, em que ocorrem também baixas taxas de evapotranspiração. Já nos períodos de março e dezembro as precipitações são inferiores a $145 \mathrm{~mm}$, com ETP que chega a 100 $\mathrm{mm} / \mathrm{mês}$ no mês de dezembro.

A tabela 2 apresenta os valores de índice de fluxo basal e recarga média mensal estimados (Figura 5) para o período de 1977 a 2006, além do percentual em relação à precipitação.

\section{Tabela 2 - Valores de BFI e recarga mensais}

\begin{tabular}{|c|c|c|c|}
\hline Mês & BFI & R (mm) & $\%$ de P \\
\hline Jan & 0,55 & 21,1 & $15 \%$ \\
\hline Fev & 0,53 & 23,4 & $17 \%$ \\
\hline Mar & 0,59 & 12,1 & $11 \%$ \\
\hline Abr & 0,49 & 36,7 & $27 \%$ \\
\hline Mai & 0,50 & 44,7 & $34 \%$ \\
\hline Jun & 0,48 & 49,9 & $36 \%$ \\
\hline Jul & 0,40 & 58,8 & $33 \%$ \\
\hline Ago & 0,53 & 52,2 & $38 \%$ \\
\hline Set & 0,44 & 56,4 & $32 \%$ \\
\hline Out & 0,43 & 49,4 & $27 \%$ \\
\hline Nov & 0,53 & 31,8 & $23 \%$ \\
\hline Dez & 0,57 & 17,8 & $14 \%$ \\
\hline Média & 0,50 & 37,9 & $25 \%$ \\
\hline
\end{tabular}

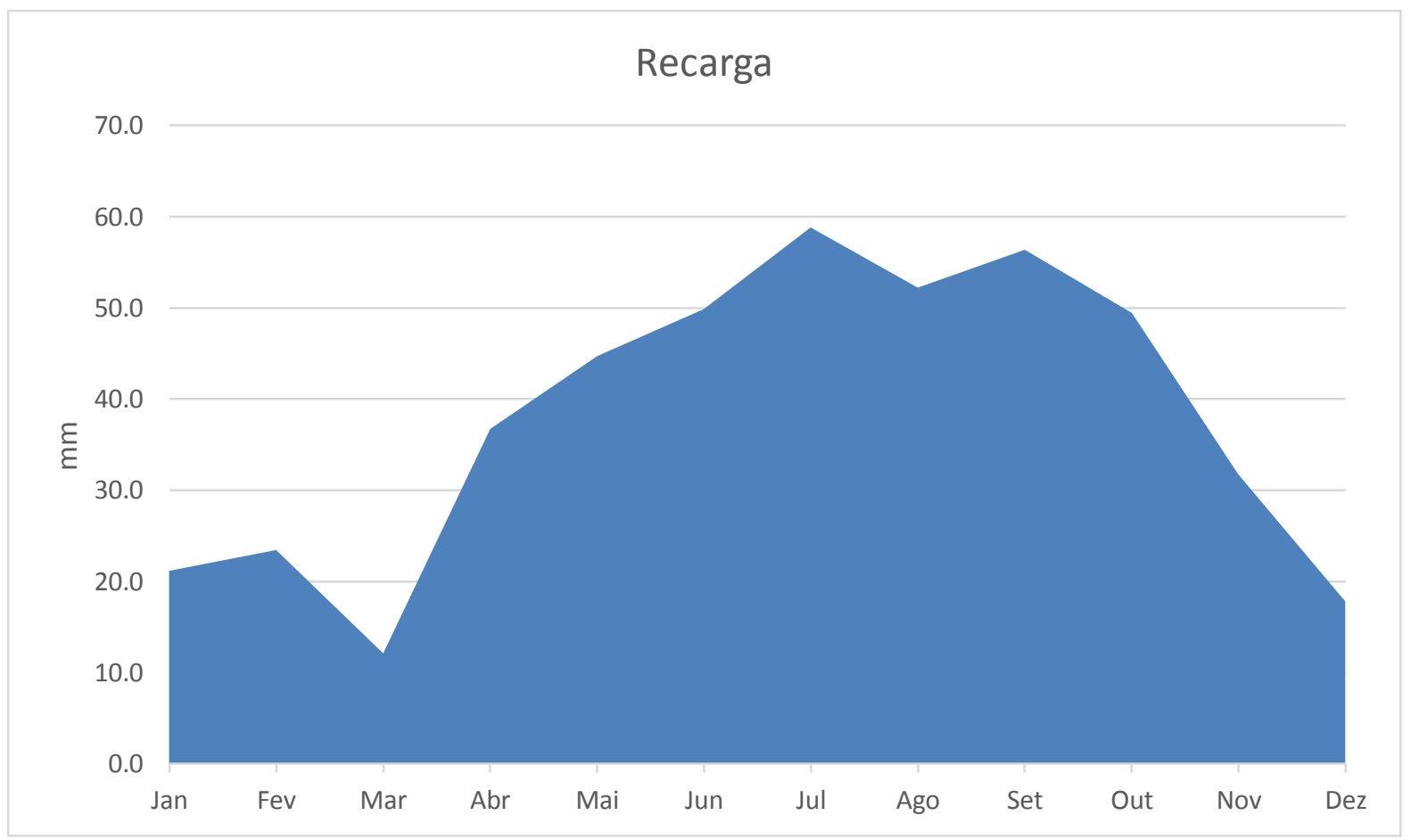

Figura 5 - Recarga média mensal 
Observa-se uma variação mensal da estimativa de recarga, sendo que os maiores valores ocorrem nos meses de julho e setembro, apresentando valores próximos a $60 \mathrm{~mm}$. No período mais seco, as taxas de recarga são inferiores a $20 \mathrm{~mm}$ (entre dezembro e março).

O mês de março é considerado o mais seco, com precipitações médias inferiores a $111 \mathrm{~mm}$, o que contribui para uma recarga baixa, com valor um pouco superior a $12 \mathrm{~mm}$ e uma taxa que equivale a $11 \%$ da precipitação. A partir dos meses de abril e maio até o mês de outubro, onde se intensifica o período de chuvas, as taxas de recarga são maiores de $27 \%$ da precipitação que ocorre na bacia.

Nos meses de junho e julho (período do inverno) ocorrem as menores taxas de evapotranspiração, devido às menores temperaturas e taxas de insolação direta sobre a região, contribuindo para a elevação do valor da recarga. No mês de agosto ocorre a maior taxa de recarga quando comparado à precipitação $(38 \%$ de $\mathrm{P})$, sendo que a média da recarga mensal para todo o período analisa equivale a $25 \%$ da precipitação.

O comportamento ao longo dos anos é apresentado na Figura 6. A série apresenta 4 anos de falhas (1996; 2000 a 2002) que não foram considerados na análise. Observa-se uma taxa de recarga que varia de 83 a $635 \mathrm{~mm} / \mathrm{ano}$, resultado da variação das precipitações, ETP e escoamento de base utilizados para o cálculo, cuja média equivale a $18 \%$ da precipitação que ocorre na região.

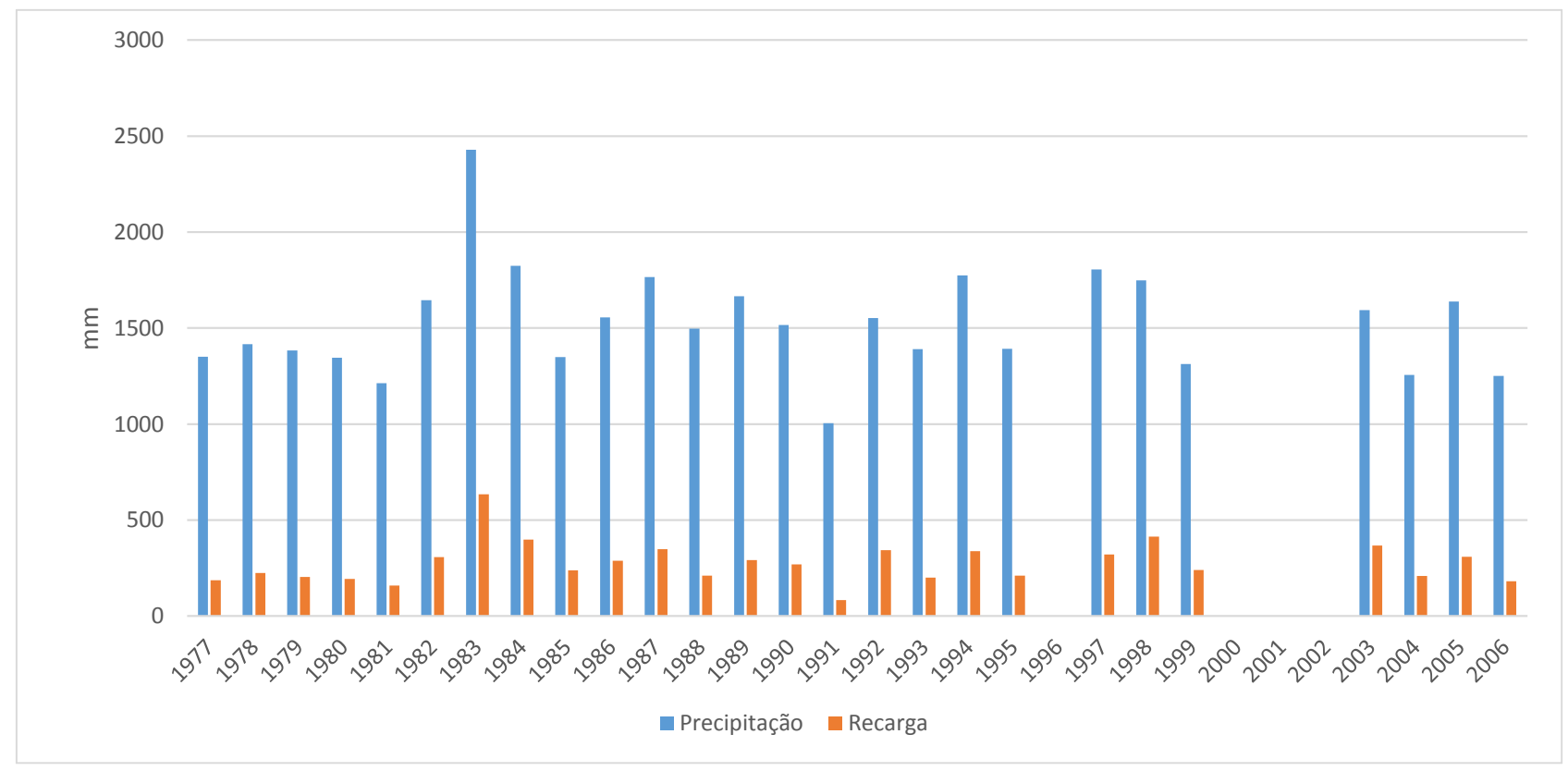

Figura 6 - Variação da precipitação e recarga anual durante o período de 1977 a 2006 


\section{Conclusões}

O método do balanço hídrico associado a um índice de fluxo basal permitiu estimar valores de recarga mensais e anuais para a bacia de estudo, os quais apresentam valores médios mensais de $25 \%$ e de $18 \%$ da recarga média anual.

Destaca-se, entretanto, que mesmo utilizando um filtro digital, o qual reduz a subjetividade na separação do escoamento, há a necessidade de aplicar outros métodos para comparação dos valores de estimativa de recarga, usando outras técnicas de separação do escoamento superficial e subterrâneo, bem como métodos de análise em campo.

Para refinamento das estimativas realizadas, é importante considerar também o modelo conceitual da recarga no sistema aquífero Serra Geral, consolidando valores mais adequados que possam ser utilizados na gestão das águas subterrâneas na região. 


\section{Referências}

ALBUQUERQUE, C. G. MONTENEGRO, S. M. G. L.; MONTENEGRO, A. A. A. JÚNIOR, R. V. P. F.; Recarga de aquífero aluvial sob uso agrícola. Águas Subterrâneas (2015) 29(1): 60-71.

CONICELLI, B. P. Gestão das Águas Subterrâneas na Bacia Hidrográfica do Alto Tietê (SP). Tese (Doutorado) - Instituto de Geociências - Universidade de São Paulo, São Paulo, 2014, 163 p.

FREITAS, S. M. A. C. Aplicação e técnicas de quantificação da Infiltração e da recarga de aquíferos do alto Rio das velhas (MG). Universidade Federal de Ouro Preto. Dissertação de Mestrado. 160p.

HEALY, R. W. Estimating groundwater recharge. RU: Cambridge University Press, 2010. 245 p.

KRESIC, N. Hydrogeology and Groundwater Modeling. EUA: CRC Press, 2007. 828 p.

LERNER DN, ISSAR AS, SIMMERS I. Groundwater recharge. A guide to understanding and estimating natural recharge. Int Contrib Hydrogeol Verlang Heinz Heise 8, 345 p., 1990.

MOURÃO M. A. A. 2007. Caracterização Hidrogeológica do Aquífero Cauê, Quadrilátero Ferrrífero, MG. Universidade Federal de Minas Gerais. Dissertação de Mestrado. 299p.

NANNI, A. S. O flúor em águas do Sistema Aquífero Serra Geral no Rio Grande do Sul: origem e condicionamento geológico. 2008. 145 f. Tese (Doutorado) - Curso de Pós-Graduação em Geociências Universidade Federal do Rio Grande do Sul, Porto Alegre, 2008.

OLIVEIRA, M. M. Aplicação de dois métodos diferentes para a estimativa da recarga de águas subterrâneas numa área de Estarreja. In: CONGRESSO DA ÁGUA, 7., 2004, Lisboa. Resumos... Lisboa: APRH, 2004. 14 p.

REGINATO, P. A. R. ; STRIEDER, Adelir José. Caracterização Hidrogeológica e Potencialidades dos Aquíferos Fraturados da Formação Serra Geral na Região Nordeste do Estado do Rio Grande do Sul. In: XIII Congresso Brasileiro de Águas Subterrâneas, 2004, Cuiabá. ANAIS DO XIII Congresso Brasileiro de Águas Subterrâneas. SÃO PAULO: ABAS, 2004. v. 1.

REGINATO, P.A.R.; STRIEDER, A.J. Caracterização Hidrogeológica dos Recursos Hídricos Subterrâneos da Formação Serra Geral na Região Nordeste do Estado do Rio Grande do Sul. In: $1^{\circ}$ SIMPÓSIO DE RECURSOS HÍDRICOS DO SUL. Santa Maria (RS). 2005. 1 CD-ROM.

RIBEIRO. J. P. M.; VELASQUEZ, L. N. M., FILHO, C. A. C.; FLEMING, P. M. Análise da recarga no sistema aquífero granular e fissural na área do campus Pampulha da Universidade Federal de Minas Gerais. Geonomos, 22(2), 28-43, 2014.

ROSSATO. Os climas do Rio Grande do Sul : variabilidade, tendências e tipologia. Tese Doutorado. Universidade Federal do Rio Grande do Sul. Instituto de Geociências. Programa de Pós-Graduação em Geografia. 2011.

ROISENBERG, A.; VIERO, A.P. 2002. O Vulcanismo Mesozoico da Bacia do Paraná no Rio Grande do Sul. In: Holz, M.; De Ros, L.F. (Edit.). Geologia do Rio Grande do Sul. Porto Alegre: CIGO/UFRGS. Porto Alegre, 2000. 444p. il.- Edição Revista, 2002.

SCANLON B. R.; KEESE, K. E.; FLINT, A. L.; FLINT, L. E; GAYE, C. B.; EDMUNDS, W. M.; SIMMERS, I. Global synthesis of groundwater recharge in semiarid and arid regions. Hydrological Process, v. 20, p. 3335-3370, 2006. 
SCANLON, B. R.; HEALY, R.; COOK, P. Choosing appropriate techniques for quantifying groundwater recharge. Hydrogeology Journal, v. 10, n. 1, p. 18-39, 2002.

SZILAGYI, J., HARVEY, F. E., AYERS, J. F., Regional estimation of base recharge to ground water using water balance and a base-flow index: Ground Water, v. 41, no. 4, p. 504-513. 2003.

THORNTHWAITE, C. W. (1948). An approach toward a rational classification of climate. Geograph. Rev., 38, 55-94.

VIERO, Ana Cláudia; SILVA, Diogo Rodrigues Andrade da (Orgs.). Geodiversidade do Estado do Rio Grande do Sul. Porto Alegre: CPRM, 2010. 1 DVD. Programa Geologia do Brasil - PGB. Levantamento da Geodiversidade.

WAHL, K. L. AND WAHL, T. L. (1988). Effects of regional ground water level declines on streamflow in the Oklahoma panhandle. In Proceedings of the Symposium on Water-Use Data for Water Resources Management, American Water Resources Association.

WAHNFRIED, I.; HIRATA, R. Comparação de Métodos de Estimativa de Recarga de Aquíferos em Uma Planície Aluvionar na Bacia Hidrográfica do Alto Tietê (São Paulo). Revista Brasileira de Recursos Hídricos Volume 10 n.2 Abr/Jun 2005, 15-25.

WILDNER, W.; ORLANDI FILHO, V.; GIFFONI, L.E. 2006. Itaimbezinho e Fortaleza, RS e SCMagníficos Cânions Esculpidos nas Escarpas Aparados da Serra do Planalto Vulcânico da Bacia do Paraná. In: Winge, M.; Schobbenhaus, C.; Berbert-Born, M.; Queiroz, E.T.; Campos, D.A.; Souza, C.R.G.; Fernandes, A.C.S. (Edit.). Sítios Geológicos e Paleontológicos do Brasil. Disponível em: 〈http://www.unb.br/ig/sigep/sitio050/sitio050.pdf〉. Publicado em: 01 jul. 2006. Acesso em: 02 jan. 2013. 